\title{
Percutaneous retrograde crossing of a near-occluded celiac trunk via the superior mesenteric artery as an adjuvant maneuver for antegrade stenting
}

\author{
Passagem retrógrada percutânea de uma lesão estenosante crítica do tronco celíaco via \\ artéria mesentérica superior como manobra adjuvante na abordagem anterógrada
}

Martin Andreas Geiger, ${ }^{1,2}$, Joren Callaert ${ }^{3}$, Koen Deloose ${ }^{3}$, Marc Bosiers ${ }^{3}$

\begin{abstract}
We describe the case of a 63-year-old woman with chronic mesenteric ischemia, persistent postprandial upper abdominal pain and progressive weight loss. Retrograde recanalization was performed via the superior mesenteric artery in order to achieve the goal of crossing the near-occlusion, showing that retrograde catheterization of the celiac trunk can be a feasible approach in challenging cases in which an antegrade approach fails as a single maneuver.

Keywords: recanalization; angioplasty; celiac trunk.

\section{Resumo}

Descrevemos o caso de uma mulher de 63 anos de idade, com isquemia mesentérica crônica, dor abdominal pós-prandial e emagrecimento progressivo. A recanalização retrógrada foi realizada através da artéria mesentérica superior para transpassar a estenose crítica. Demonstra-se assim que o cateterismo retrógrado do tronco celíaco pode ser uma abordagem viável em casos difíceis, em que a abordagem anterógrada falha como manobra única.
\end{abstract}

Palavras-chave: recanalização; angioplastia; tronco celíaco. 


\section{INTRODUCTION}

Chronic mesenteric ischemia (CMI) is a rare pathology that is generally caused by atherosclerotic disease resulting in progressive stenosis or occlusion of one or more mesenteric arteries. ${ }^{1}$ Symptoms are often nonspecific, presenting as postprandial abdominal pain, weight loss and even diarrhea. ${ }^{2}$

Endovascular surgery isn't yet considered the golden standard, which remains open surgery, because the endovascular technique is associated with frequent reinterventions and technical limitations. Nevertheless, it is a treatment that offers shorter hospital stays and has low morbidity and mortality. ${ }^{3}$

It is essential to treat symptomatic $\mathrm{CMI}$ in order to avoid progression of the disease to acute mesenteric ischemia, which occurs in $40 \%$ to $50 \%$ of these patients. ${ }^{1,4}$

Endovascular treatment is the most viable choice for patients with CMI and high operative risk, but percutaneous treatment of a near-occluded celiac trunk (CT) can make the procedure extremely difficult., ${ }^{2,3}$ It is often necessary to use alternative techniques, such as retrograde recanalization, or even hybrid approaches. ${ }^{5}$

We describe the case of a patient with near-occlusion of the $\mathrm{CT}$ and occlusion of the inferior mesenteric artery (IMA) who was treated with retrograde crossing of the lesion via the superior mesenteric artery (SMA) and antegrade stenting, resulting in complete resolution of symptoms.

\section{PART I - CLINICAL SITUATION}

A 63-year-old woman was referred from the Gastrointestinal Department with a history of smoking (stopped 10 years ago), chronic arterial hypertension, chronic obstructive pulmonary disease and hypercholesterolemia, after presenting with a history of 6 months of postprandial upper abdominal pain. The patient had exhibited progressive weight loss of $4 \mathrm{~kg}$ during this period and showed no signs of vomiting or melena.

Colonoscopy and gastrointestinal endoscopy findings were normal. Abdominal ultrasound revealed a previous cholecystectomy with no other important results.

Computed angiotomography showed diffuse aortic atherosclerotic disease with near-occlusion of the CT, low-grade stenosis at the level of the ostium of the SMA and occlusion of the IMA(Figure 1). The patient was diagnosed with CMI secondary to an atherosclerotic near-occluded CT and an occluded IMA.

\section{PART II - WHAT WAS DONE}

The right common femoral artery was accessed percutaneously and a $6 \mathrm{Fr}, 65 \mathrm{~cm}$ sheath (Destination; Terumo, Tokyo, Japan) was positioned into the abdominal aorta. A coaxial catheter technique with different angulated catheters (e.g., Glidecath; Terumo, Tokyo, Japan) was used to attempt an antegrade crossing of the lesion, but without success. Superselective angiography of the SMA with an angulated catheter (RIM; Cook, Indiana, USA) confirmed a near-occluded $\mathrm{CT}$ ostium and a well-developed connection between the SMA and the CT (Figure 2). A 0.018" hydrophilic guidewire (Advantage; Terumo, Tokyo, Japan) was

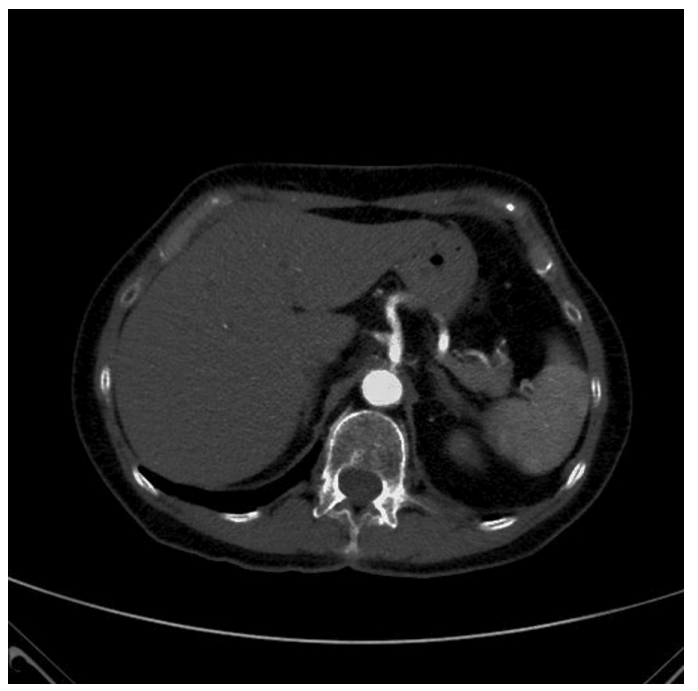

Figure 1. Diffuse aortic atherosclerotic disease with near-occlusion of the celiac trunk.

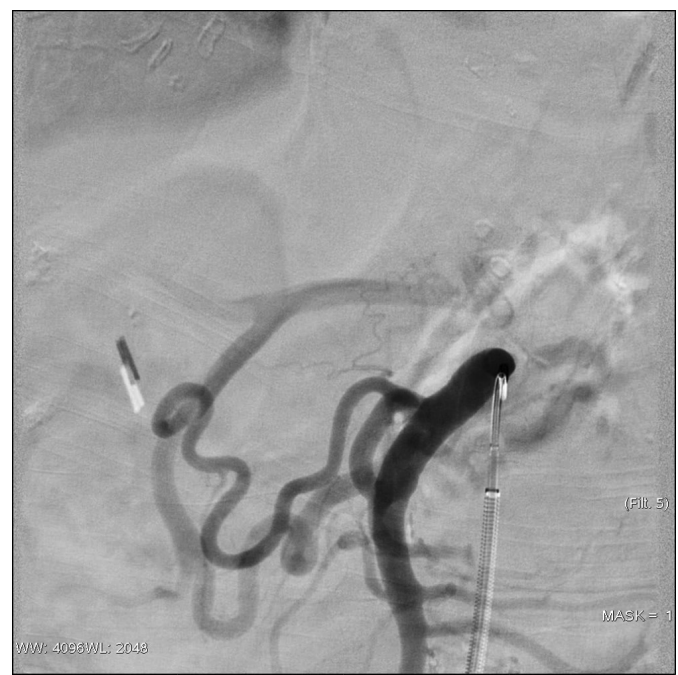

Figure 2. Well-developed connection between the SMA and the CT. 
passed into the SMA from the same diagnostic catheter, reaching the near-occlusion of the $\mathrm{CT}$ in the retrograde direction. A microcatheter (Renegade; Boston Scientific Corporation, Massachusetts, USA) was advanced over the wire until it reached the same point (Figure 3). The lesion was then crossed with a 0.014" wire (Advantage; Terumo, Tokyo, Japan), which was followed by the microcatheter. The lesion was sequentially dilated with short 2, 3 and $4 \mathrm{~mm}$ over-the-wire, low profile 0.014 " balloons (Armada 14; Abbott Vascular, Illinois, USA) with no sign of embolization or dissection. No imaging was performed during the ballooning process. Retrograde stenting of the lesion wasn't feasible due to tortuosity. Therefore another antegrade attempt was made, since the ostium

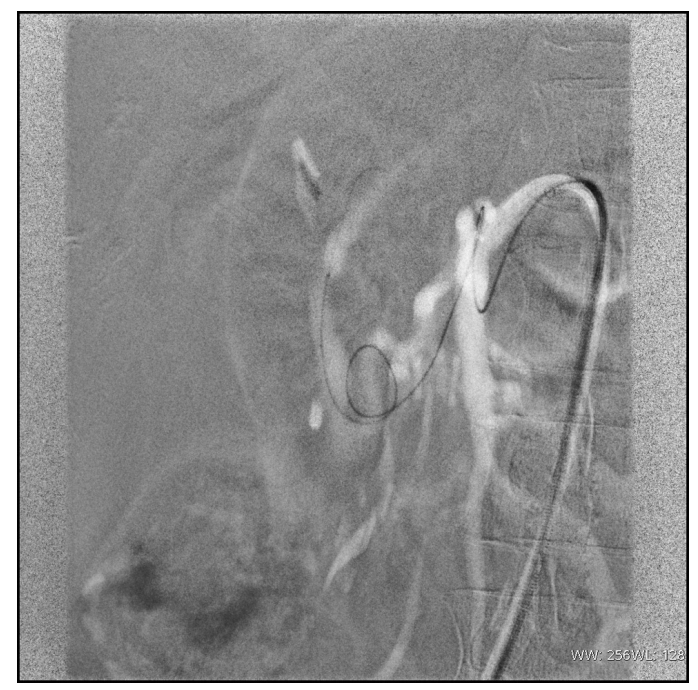

Figure 3. A microcatheter was advanced over the wire.

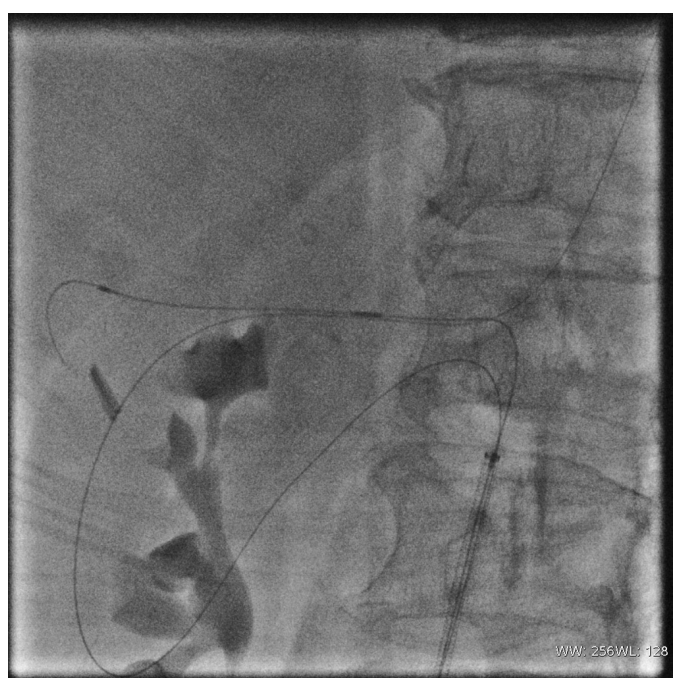

Figure 4. A wire was placed into the hepatic artery in the antegrade direction. of the CT was known. A 0.014" wire (Stabilizer, Cordis, NJ, USA) was placed into the hepatic artery in the antegrade direction, through the hole provided by the previous ballooning; no capture device was needed (Figure 4). The retrograde wire was retracted (Figure 2). The ostium was stented with a $6 \times 15-\mathrm{mm}$ balloon-expandable stent (Figure 5) (Herculink Elite, Abbott Vascular, Illinois, USA).

Final angiography showed antegrade flow into the $\mathrm{CT}$ and SMA with no residual stenosis or any signs of dissection (Figure 6). No complications were reported and the patient was discharged 2 days after the procedure on antiplatelet treatment consisting of $100 \mathrm{mg} / \mathrm{d}$ of aspirin combined with $75 \mathrm{mg} / \mathrm{d}$ of clopidogrel. Follow-up at 1 and 6 months with US

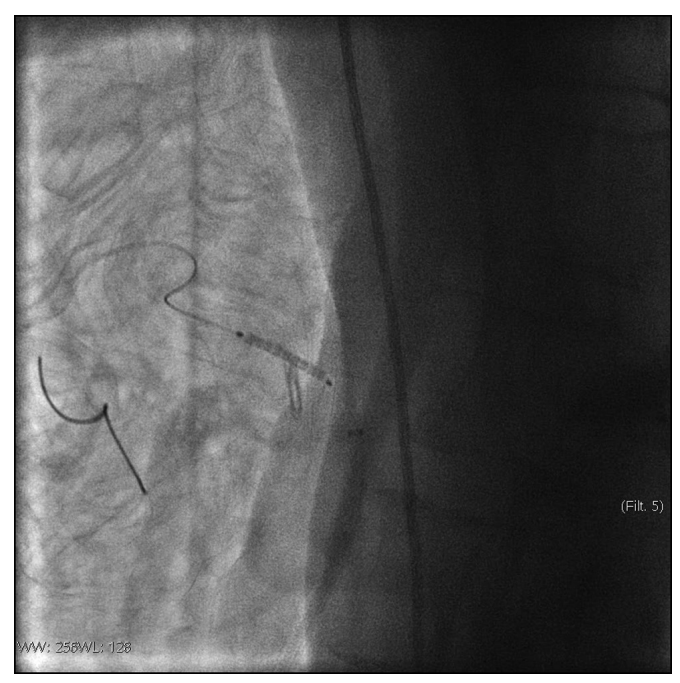

Figure 5. The ostium was stented with a $6 \times 15-\mathrm{mm}$ balloonexpandable stent.

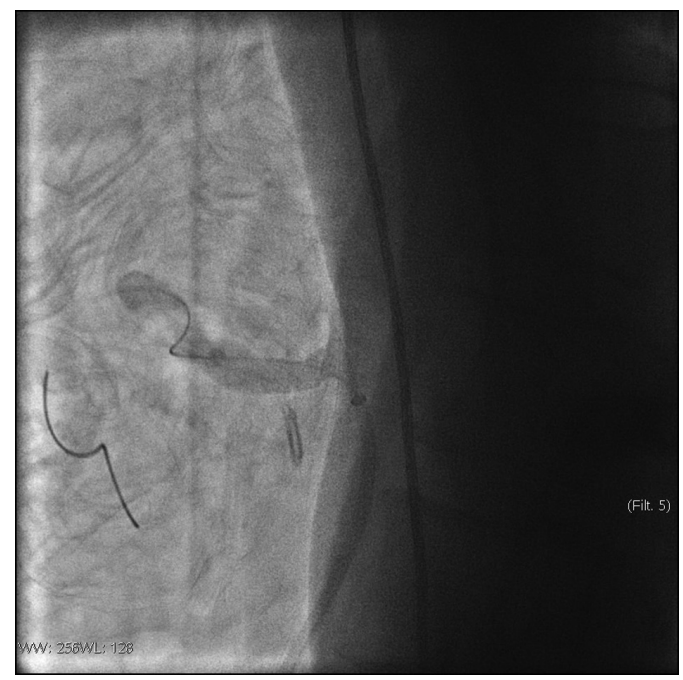

Figure 6. Final angiography showed antegrade flow into the CT, with no residual stenosis. 


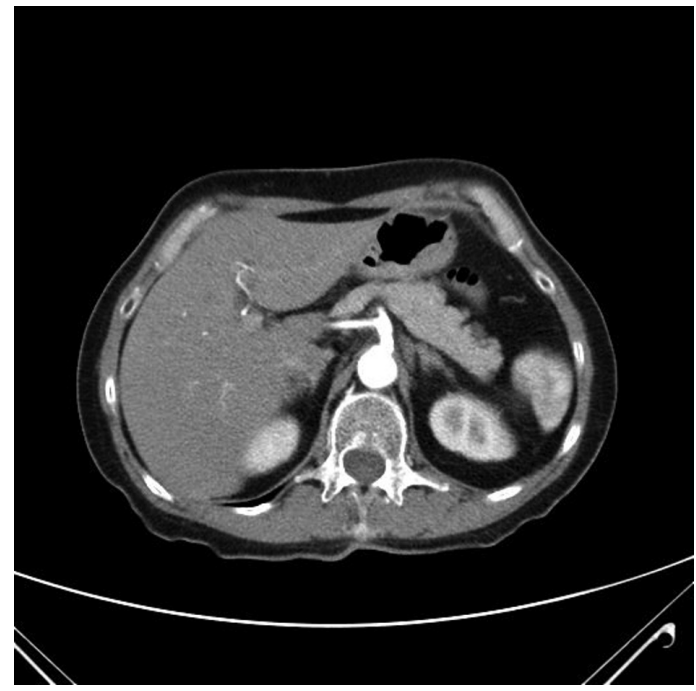

Figure 7. Follow-up at 6 months with angiotomography showed that the CT was still patent.

and angiotomography showed that the CT was still patent and there were no signs of recurrence of the symptoms (Figure 7).

\section{DISCUSSION}

Chronic mesenteric ischemia is a rare disease that is generally caused by progressive stenosis or occlusion of one or more mesenteric arteries. Several authors have discussed the minimum number of diseased vessels for symptoms to appear, based on ultrasound studies showing critical stenosis of at least one mesenteric artery in up to $17.5 \%$ of asymptomatic people over 65 years old, although other authors recognize that in $9 \%$ of chronic cases symptomatic involvement is only in one artery (5\% with SMA and $4 \%$ with CT involvement). ${ }^{1,6}$

Classic symptoms include postprandial abdominal pain, "food fear" and weight loss, but often these symptoms are nonspecific and present real diagnostic challenges for most specialists. ${ }^{1}$ Most patients who are diagnosed with CMI will undergo extensive investigation, with expensive and sometimes inconclusive exams. ${ }^{1}$

Chronic mesenteric ischemia has predictive value and should be treated, since $50 \%$ of patients with acute mesenteric ischemia have previously exhibited symptoms of CMI. ${ }^{4}$ The mortality rate among patients with acute mesenteric ischemia is as high as $40 \%$ to $50 \%{ }^{6}$ It is an extremely debilitating disease leading to reduced quality of life and weight loss due to malnutrition.

The open surgical approach is the gold standard for treatment of CMI, but there is no consensus on the best method of revascularization. Several reports have compared open repair with endovascular treatment and the endovascular approach has achieved a high rate of technical success and lower rates of morbidity and mortality outcomes over the short term, especially when dealing with high-risk patients. ${ }^{2,6-8}$ The normal antegrade endovascular approach to a diseased CT is via femoral or brachial access.

In this case, we chose to use the retrograde approach via the common femoral artery. Brachial access was avoided because of the fragile appearance and very small size of the brachial artery, confirmed by ultrasound.

Stent placement was chosen because the results of ballooning were unsatisfactory and because of its superior late patency compared with percutaneous transluminal angioplasty alone for treatment of calcified ostial stenosis/occlusion. ${ }^{7}$

Retrograde catheterization is a well-established approach for peripheral recanalization and is presented here as a feasible alternative for endovascular CMI treatment, especially when antegrade recanalization fails. ${ }^{9,10}$ It is also possible to exit the retrograde wire through a second access before continuing the treatment in the antegrade direction, but that technique requires a capture device. ${ }^{9}$

Once the arterial lumen had been achieved, as confirmed by angiogram after the progressive angioplasty, we chose to continue with an antegrade approach. Stent placement was not possible via the retrograde approach because of the device's rigidity and the tortuosity of the vessels. The antegrade approach offered greater stability and enabled better accuracy for positioning the stent.

\section{CONCLUSION}

With this case we demonstrate that retrograde crossing of a CT lesion is a feasible technique, allowing antegrade catheterization and further stenting of the vessel, adding another approach to the arsenal available to vascular surgeons faced with challenging lesions and enabling more complete and less invasive treatment.

\section{REFERENCES}

1. Kougias P, El Sayed HF, Zhou W, Lin PH. Management of chronic mesenteric ischemia: the role of endovascular therapy. J Endovasc Ther. 2007;14(3):395-405. http://dx.doi.org/10.1583/07-2102.1. PMid:17723025.

2. Fioole B, van de Rest HJ, Meijer JR, et al. Percutaneous transluminal angioplasty and stenting as first-choice treatment in patients with chronic mesenteric ischemia. J Vasc Surg. 2010;51(2):386-91. http://dx.doi.org/10.1016/j.jvs.2009.08.055. PMid:19889510. 
3. Sharafuddin MJ, Nicholson RM, Kresowik TF, Amin PB, Hoballah JJ, Sharp WJ. Endovascular recanalization of total occlusions of the mesenteric and celiac arteries. J Vasc Surg. 2012;55(6):1674-81. http://dx.doi.org/10.1016/j.jvs.2011.12.013. PMid:22516890.

4. Peck MA, Conrad MF, Kwolek CJ, LaMuraglia GM, Paruchuri V, Cambria RP. Intermediate-term outcomes of endovascular treatment for symptomatic chronic mesenteric ischemia. J Vasc Surg. 2010;51(1):140-7. http://dx.doi.org/10.1016/j.jvs.2009.06.064. PMid:19837530.

5. Sonesson B, Hinchliffe RJ, Dias NV, Resch TA, Malina M, Ivancev K. Hybrid recanalization of superior mesenteric artery occlusion in acute mesenteric ischemia. J Endovasc Ther. 2008;15(1):129-32. http://dx.doi.org/10.1583/07-2210.1. PMid:18254664.

6. Atkins MD, Kwolek CJ, LaMuraglia GM, Brewster DC, Chung TK, Cambria RP. Surgical revascularization versus endovascular therapy for chronic mesenteric ischemia: a comparative experience.J Vasc Surg. 2007;45(6):1162-71. http://dx.doi.org/10.1016/j.jvs.2007.01.067. PMid:17467950.

7. Sharafuddin MJ, Olson CH, Sun S, Kresowik TF, Corson JD. Endovascular treatment of celiac and mesenteric arteries stenoses: applications and results. J Vasc Surg. 2003;38(4):692-8. http:// dx.doi.org/10.1016/S0741-5214(03)01030-9. PMid:14560214.

8. Sarac TP, Altinel O, Kashyap V, et al. Endovascular treatment of stenotic and occluded visceral arteries for chronic mesenteric ischemia. J Vasc Surg. 2008;47(3):485-91. http://dx.doi.org/10.1016/j. jvs.2007.11.046. PMid:18295100.

9. Ferro C, Rossi UG, Seitun S, Bovio G, Fornaro R. Endovascular treatment of totally occluded superior mesenteric artery by retrograde crossing via the Villemin arcade. Cardiovasc Intervent Radiol. 2013;36(3):848-52. http://dx.doi.org/10.1007/s00270-0120469-y. PMid:22923330.
10. Montero-Baker M, Schmidt A, Braunlich S, et al. Retrograde approach for complex popliteal and tibioperoneal occlusions. J Endovasc Ther. 2008;15(5):594-604. http://dx.doi.org/10.1583/082440.1. PMid: 18840044

Correspondence Martin Andreas Geiger Hospital de Clínicas da Universidade Estadual de Campinas - HCUNICAMP, Departamento de Cirurgia Rua Tessália Vieira de Camargo, 126 - Cidade Universitária Zeferino

CEP 13083-887 - Campinas (SP), Brazi Tel.: +55 (19) 3521-9450 E-mail: martinandreasgeiger@yahoo.com.br

Author information MAG - Vascular surgeon at Hospital de Clínicas da Universidade Estadual de Campinas (HC-UNICAMP) and Hospital da PUCCampinas (PUCC) JC and KD - Vascular surgeons at Hospital Sint Blasius. MB - Vascular surgeon and chief of staff at Hospital Sint Blasius.

Author contributions Conception and design: MAG, JC Analysis and interpretation: MAG, JC

Data collection: MAG, JC Writing the article: MAG, JC Critical revision of the article: MAG, JC, KD, MB Final approval of the article*: MAG, JC, KD, MB Statistical analysis: N/A Overall responsibility: MAG, JC, KD, MB

*All authors have read and approved of the final version of the article submitted to I Vasc Bras. 